\title{
Comparative biases from pushnet and pullnet zooplankton samples
}

\author{
Ann Hillmann-Kitalong \& Charles Birkeland
}

Marine Laboratory, UOG Station, Mangilao, Guam 96923

\begin{abstract}
Biases in pushnet and pullnet zooplankton samples were investigated by obtaining paired samples sequentially with the 2 types of net, alternating the order of net type to control for the effect of order. There were no significant differences between pushnet and pullnet samples in total numbers of zooplankton, dry weight, or ash-free dry weight. Daytime pullnet samples contained significantly greater numbers of relatively passive drifters (fish eggs, invertebrate eggs, and siphonophores). There were no such differences among samples taken on moonless nights. Copepods (Acartia spp.) were more abundant in pushnet than in pulnet samples in all 32 pairs of daylight samples, but not at night. Therefore, the bias for motile zooplankton probably resulted from avoidance influenced by light. The greater abundance of floating eggs in pullnet samples may have been a result of mixing the surface water with water $60 \mathrm{~cm}$ below by turbulence created by the boat hull and the propeller There were generally no significant interactions in results between net type and date or location, therefore either pushnet or pullnet could be used in studies to test hypotheses because statistical analysis requires a standardized sampling technique within the program and because without interaction, any bias should be consistent across the sampling program. However, since all methods for sampling zooplankton are probably biased, a variety of sampling methods should be used in combination for estimating parameters.
\end{abstract}

\section{INTRODUCTION}

While planning a study of effects of water current patterns on zooplankton communities around Guam, we became concerned that towing a pair of nets behind our boat would give biased results because some groups of zooplankton could avoid nets more effectively than others in reaction to disturbance by the boat, the outboard propeller, and the towing line and bridle. Also, there may be added variance in samples resulting from letting out and pulling in nets held on a $10 \mathrm{~m}$ line. We predicted that nets attached to rigid frames near the bow of a boat ('pushnets'), at a less variable depth, would significantly reduce the sampling problems caused by these factors. We decided to take a series of samples to compare the results obtained by pushing with those obtained by pulling zooplankton nets.

\section{METHODS}

All nets were $0.35 \mathrm{~mm}$ mesh and $50 \mathrm{~cm}$ diameter. The speed of the boat was adjusted to about 1.3 knots before beginning sampling. The $22 \mathrm{ft}(6.7 \mathrm{~m})$ boat was set to a speed at which it moved its own length past a floating object (e.g. an orange peel) in $10 \mathrm{~s}$. Three measurements were taken to verify boat-speed before the nets were lowered into the water. All samples were taken during $4 \mathrm{~min}$ tows. Therefore, each sample was from about $32 \mathrm{~m}^{3}$ of water.

In order to push a pair of zooplankton nets at a depth of about $60 \mathrm{~cm}$ near the bow of the boat, the rim of each zooplankton net was attached to hooks welded to the inner 4 sides of a steel frame. The steel frames were attached to galvanized pipes that passed through sleeves bolted to the 2 sides of the bow of the boat (Fig. 1). The nets were simultaneously pivoted into the water with levers on the proximal end of the pipe. When the nets were lifted from the water, they could be raised and lowered to rinse them. After they were rinsed, the nets on the frames were brought in by sliding the pipes inward through the sleeves. While samples were being taken, the frame was held in a vertical position against the force of water by stainless steel cables. One man could pivot both nets upward with the levers as the boat slowed to a stop. Other designs of pushnet systems are described by Miller (1973) and by Kriete \& Loesch (1980). 


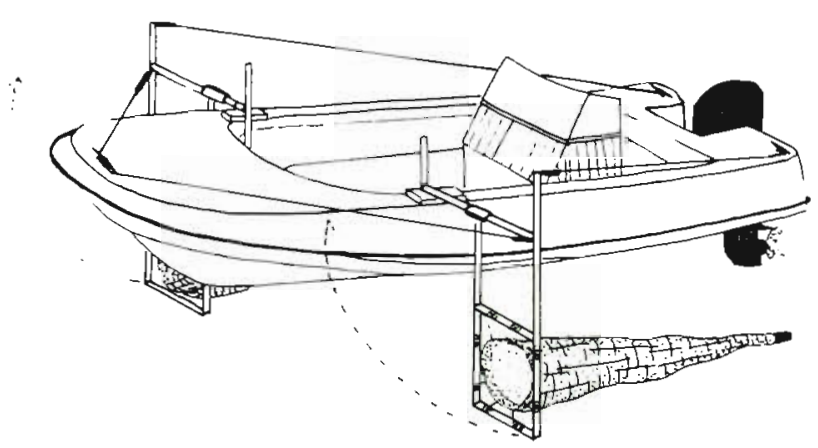

Fig. 1. Design of pushnet apparatus consisting of stainless steel support cables and a galvanized steel frame with net diameter $50 \mathrm{~cm}$. Broken arrows indicate the movement of the frame to collect samples and rinse nets and position of frame for travel between sites

Pairs of pullnet samples were taken by towing with about $10 \mathrm{~m}$ of polypropylene rope, each attached to a cleat on either side of the stern. Minor adjustments of this length were made to keep the nets centered at about $60 \mathrm{~cm}$ depth, with the top of the net at about $35 \mathrm{~cm}$ depth.

Pairs of pushnet samples and pullnet samples were taken sequentially rather than simultaneously to avoid variable effects of the pushnet on the pullnet samples. Each set of samples at a particular place and time consisted of 4 pairs, 2 push and 2 pull, for a total of 8 . The sequence was push-pull-pull-push or pull-pushpush-pull.

The sampling program involved 4 factors: method (pushnet or pullnet); time (daytime samples between 1000 and $1200 \mathrm{~h}$ and night-time samples about $9 \mathrm{~h}$ later, on moonless nights between 1930 and $2030 \mathrm{~h}-$ sunset was about $1830 \mathrm{~h}$ ); site (a fast-current area and slow-current area); and date (3 dates for daytime, with night-time samples taken on 2 of the dates). Method, time, and site were considered Model I (fixed) factors; date was considered a Model II (random) factor (Sokal
\& Rohlf 1981). Four samples (2 passes with 2 nets) in each cell made up the error variance.

It was decided later to further partition the analysis to take the starboard and port nets as an additional fixed factor. A 5-way mixed analysis of variance (ANOVA) for each of the 8 prevalent taxa showed that the differences between starboard and port nets, differences between replicate passes, and interactions of nets or passes with other variables were not significant. The variance between passes was about 20 times the magnitude of the variance between nets, but first and second passes each had the greater catch of plankton about half the time. Since no differences or interaction were found, since the original 4 factors showed the same relative effects whether in 4-way or 5-way ANOVA, and since the table displaying the non-significant interactions between 5 factors for 8 taxa was too bulky to display for no useful information, we reverted to the consideration of the 2 passes with 2 nets as replicate samples.

\section{RESULTS}

Analysis was done for each of the 8 most prevalent groups of plankton in the samples: Acartia spp., Sagitta spp., mysids, crab zoeae, fish larvae, fish eggs, invertebrate eggs, and siphonophores (Table 1). Only adult Acartia spp. (1 mm or greater) were counted. A 4-way ANOVA between site, dates, times, and methods showed time (daytime or night-time) to be the most influential factor for each of the 8 prevalent taxa. The effects of day-night differences permeated all aspects of the analysis with significant $(p<0.001)$ interactions between time and each of the other factors; so to clarify the effects of other factors, 3-way ANOVA on sites, dates, and methods were done separately for daytime and night-time samples (Table 2).

Table 1. Mean abundances (no. $\mathrm{m}^{-3}$ ) of the 8 most prevalent groups of zooplankton in day and night samples by pushnets and pullnets

\begin{tabular}{|c|c|c|c|c|c|c|}
\hline \multirow[t]{2}{*}{ Group } & \multicolumn{3}{|c|}{$\begin{array}{l}\text { Daytime samples } \\
(\overline{\bar{Y}} \pm S)\end{array}$} & \multicolumn{3}{|c|}{$\begin{array}{c}\text { Night-time samples } \\
(\bar{Y} \pm S)\end{array}$} \\
\hline & Push $(\mathrm{n}=24)$ & & Pull $(\mathrm{n}=24)$ & Push $(n=16)$ & & Pull $(\mathrm{n}=16)$ \\
\hline \multicolumn{7}{|l|}{ Motile zooplankton } \\
\hline Acartia spp. & $3.3 \pm 1.6$ & $>$ & $1.2 \pm 1.2$ & $0.5 \pm 1.1$ & $>$ & $0.4 \pm 1.5$ \\
\hline Sagitta spp. & $3.6 \pm 5.0$ & $>$ & $1.7 \pm 0.8$ & $1.0 \pm 1.5$ & $>$ & $0.5 \pm 1.0$ \\
\hline Crab zoea & $1.4 \pm 3.0$ & $>$ & $0.1 \pm 0.1$ & $23.9 \pm 18.6$ & $>$ & $22.6 \pm 21.4$ \\
\hline Mysids & $0.7 \pm 2.0$ & $>$ & 0 & $27.3 \pm 18.4$ & $>$ & $15.4 \pm 11.6$ \\
\hline Fish larvae & $0.08 \pm 0.08$ & $>$ & $0.05 \pm 0.07$ & $2.3 \pm 2.1$ & $>$ & $1.1 \pm 0.6$ \\
\hline \multicolumn{7}{|c|}{ Relatively passive drifters } \\
\hline Fish eggs & $19.7 \pm 13.8$ & $<$ & $21.6 \pm 10.1$ & $14.2 \pm 2.1$ & $>$ & $6.2 \pm 6.5$ \\
\hline Invertebrate eggs & $8.4 \pm 7.2$ & $<$ & $9.0 \pm 8.0$ & $3.0 \pm 5.0$ & $<$ & $3.3 \pm 5.3$ \\
\hline Siphonophores & $4.4 \pm 5.3$ & $<$ & $5.3 \pm 5.5$ & $0.8 \pm 1.7$ & $=$ & $0.8 \pm 1.9$ \\
\hline
\end{tabular}


Table 2. Probabilities of exceeding the values of F-statistics in 16 3-way ANOVAs performed for samples collected in midday and on moonless nights for each of 8 taxa

\begin{tabular}{|c|c|c|c|c|c|c|c|c|}
\hline \multirow[t]{2}{*}{ ANOVA } & \multicolumn{5}{|c|}{ Motile zooplankton } & \multicolumn{3}{|c|}{ Relatively passive drifters } \\
\hline & $\begin{array}{c}\text { Acartia } \\
\text { spp. }\end{array}$ & $\begin{array}{l}\text { Sagitta } \\
\text { spp. }\end{array}$ & Mysids & $\begin{array}{c}\text { Crab } \\
\text { zoeae }\end{array}$ & $\begin{array}{l}\text { Fish } \\
\text { larvae }\end{array}$ & $\begin{array}{l}\text { Fish } \\
\text { eggs }\end{array}$ & $\begin{array}{c}\text { Invertebrate } \\
\text { eggs }\end{array}$ & $\begin{array}{l}\text { Siphono- } \\
\text { phores }\end{array}$ \\
\hline \multicolumn{9}{|c|}{ Daytime samples $(n=48)$} \\
\hline Site (S) & $<0.0001$ & 0.0596 & $<0.0001$ & 0.0425 & 0.9970 & 0.6170 & 0.8095 & $<0.0001$ \\
\hline Date (D) & $<0.0001$ & $<0.0001$ & $<0.0001$ & 0.0002 & 0.0229 & $<0.0001$ & $<0.0001$ & $<0.0001$ \\
\hline Method (M) & $<0.0001$ & 0.7294 & $<0.0001$ & 0.2171 & 0.0509 & 0.0084 & 0.6437 & 0.4975 \\
\hline$S \times M$ & 0.1621 & 0.7726 & $<0.0001$ & 0.3823 & 0.9376 & 0.5008 & 0.6935 & 0.4904 \\
\hline$D \times M$ & 0.0021 & 0.2142 & $<0.0001$ & 0.5375 & 0.7967 & 0.8354 & 0.2494 & 0.0196 \\
\hline$S \times D$ & $<0.0001$ & 0.0074 & $<0.0001$ & 0.0054 & 0.0096 & $<0.0001$ & 0.0003 & $<0.0001$ \\
\hline $\mathrm{S} \times \mathrm{D} \times \mathrm{M}$ & 0.4892 & 0.0264 & $<0.0001$ & 0.6985 & 0.9295 & 0.2527 & 0.8412 & 0.0285 \\
\hline \multicolumn{9}{|c|}{ Night-time samples $(n=32)$} \\
\hline Site (S) & 0.6553 & 0.0027 & 0.2003 & 0.1138 & 0.0057 & $<0.0001$ & $<0.0001$ & $<0.0001$ \\
\hline Date (D) & 0.4933 & 0.0008 & 0.3694 & 0.5889 & 0.4450 & 0.6415 & $<0.0001$ & $<0.0001$ \\
\hline Method (M) & 0.4933 & 0.1026 & 0.0105 & 0.6599 & 0.0281 & 0.0627 & 0.8935 & $<0.2261$ \\
\hline $\mathrm{S} \times \mathrm{M}$ & 0.6746 & 0.4590 & 0.0526 & 0.2600 & 0.0863 & 0.9857 & 0.0261 & 0.5368 \\
\hline $\mathrm{D} \times \mathrm{M}$ & 0.0047 & 0.8312 & 0.0090 & 0.0354 & 0.1852 & 0.0578 & 0.0192 & 0.2444 \\
\hline $\mathrm{S} \times \mathrm{D}$ & 0.6746 & 0.0130 & 0.0030 & 0.2877 & 0.6982 & 0.2923 & 0.0031 & $<0.0001$ \\
\hline$S \times D \times M$ & 0.6553 & 0.1916 & 0.1250 & 0.5086 & 0.5280 & 0.4052 & 0.9958 & 0.5057 \\
\hline
\end{tabular}

For daytime samples, the catches differed significantly $(p<0.001)$ between days among the sites for all groups except fish larvae, but the interaction between dates and sites obscured any pattern other than overall variability among the samples (Table 2 ). The catches from pushnet and pullnet samples, however, differed significantly $(p<0.001)$ for Acartia spp. and mysids, although interactions between methods and dates or sites were also significant (Table 2). Motile zooplankton were caught in greater numbers in pushnet samples, and passive drifters were caught in greater numbers in pullnet samples (Table1). We tallied the number of times each zooplankton group was more numerous in

Table 3. Frequencies of greater abundances in paired samples of pushnets and pullnets. Samples with each net type were paired with the other net type taken sequentially, alternately a few minutes before or after, at the same site. Total sample sizes vary because zeroes or other ties were not counted

\begin{tabular}{|c|c|c|c|c|}
\hline \multirow[t]{2}{*}{ Group } & \multicolumn{2}{|c|}{ Daytime samples } & \multicolumn{2}{|c|}{ Night-time samples } \\
\hline & Push & Pull & Push & Pull \\
\hline Acartia spp. & 32 & 0 & 4 & 3 \\
\hline Sagitta spp. & 9 & 6 & 6 & 4 \\
\hline Crab zoeae & 9 & 1 & 9 & 6 \\
\hline Mysids & 4 & 0 & 6 & 9 \\
\hline Fish larvae & 7 & 3 & 11 & 4 \\
\hline $\begin{array}{l}\text { Total motile } \\
\text { zooplankton }\end{array}$ & 61 & 10 & 36 & 26 \\
\hline Fish eggs & 9 & 23 & 12 & 4 \\
\hline Invertebrate eggs & 8 & 8 & 4 & 4 \\
\hline Siphonophores & 7 & 8 & 5 & 1 \\
\hline $\begin{array}{l}\text { Total passive } \\
\text { drifters }\end{array}$ & 24 & 39 & 21 & 9 \\
\hline
\end{tabular}

the pushnet or pullnet samples (Table 3). A sign test showed the motile groups of zooplankton as a whole to be more abundant more frequently in the pushnet samples $\left(t_{5|70|}=6.05, p<0.001\right)$; the tendency for passive drifters to be more abundant in pullnet samples was not quite significant $\left(t_{5|63|}=1.89, p=0.067\right)$.

The night-time samples usually did not show significant differences between sites or between dates, and the differences between pushnet and pullnet samples were not consistent or significant for samples taken at night $\left(\mathrm{t}_{\mathrm{s} \mid 61]}=1.27, \mathrm{p}>0.2\right)$.

There were no significant differences by paired-comparisons tests in total amounts of zooplankton in pushnet and pullnet samples for dry weight of zooplankton (pushnet, $0.167 \pm 0.058 \mathrm{~g}$ per sample; pullnet, $0.171 \pm$ $0.048 \mathrm{~g}$ per sample; $\left.t_{s(15 \mid}=0.116\right)$, for ash-free dry weight (pushnet, $0.039 \pm 0.035 \mathrm{~g}$ per sample; pullnet, $0.042 \pm 0.032$ g per sample; $\left.t_{s \mid 15\}}=0.294\right)$, and for total numbers of zooplankters (pushnet, $2699 \pm 2318$; pullnet, $\left.2522 \pm 1928 ; t_{s[23 \mid}=0.282\right)$.

\section{DISCUSSION}

Pushnet samples contained more motile zooplankton than did replicate pullnet samples during the day. This tendency was not significant at night. This suggests that the avoidance reaction of zooplankton to nets that are pulled behind a boat involves light. Perhaps the motile zooplankton react to increased water turbulence or to the bow wake photonegatively. The importance of light was particularly evident for Acartia spp. because the probability of pushnet samples having more indi- 
viduals of Acartia spp. than the pullnet samples on all 32 daytime samples was $p=(1 / 2)^{32}=2.3 \times 10^{-10}$ while the probability of the pushnet samples having more than the pullnet samples in 4 out of the 7 pairs of night-time samples which contained Acartia spp. was $p=0.50$.

In contrast, non-motile zooplankton tended to be more abundant in pullnet samples in the daytime. For example, the probability of fish eggs being more common in pullnets in 23 pairs of tows and in pushnets in 9 pairs was 0.019 (sign test, $t_{s[31]}=2.47$ ). If fish eggs float and are near the surface, the pushnets may have tended to miss the fish eggs because the nets were fixed in position with their centers at a depth of about $60 \mathrm{~cm}$ and their upper edges at about $35 \mathrm{~cm}$. The pullnets were held at the same depth but they were not fixed as rigidly in position. Furthermore, the pullnets were about $10 \mathrm{~m}$ behind the hull of the boat and propeller, both of which tended to mix the water, perhaps bringing some of the floating organisms in the surface layer into the path of the net.

All taxa in this study, except siphonophores, showed similar day-night differences in abundances as had been found in previous studies in Guam (Randall \& Eldredge 1982, Hillmann-Kitalong 1983). The significant differences in the abundances of some of these taxa between dates and time have been attributed to lunar reproductive cycles and may also be the result of vertical diurnal migration. One study of diurnal patterns (Hillmann-Kitalong 1983) found that an Acartia sp. and Sagitta enflata were significantly more abundant at, and chlorophyll a values were high at, 0700 to $0900 \mathrm{~h}$. This suggests that Acartia spp. may be feeding on phytoplankton and $S$. enflata may be feeding on Acartia spp. at the surface during the day and moving downward at night. In contrast, mysids were found close to sandy bottoms and within coral crevices during the day (pers. obs. in Guam using SCUBA) and may be migrating upward at night to feed. The greater abundance of crab zoeae at night may be the result of the release of developed zoeae by adult females at dusk on a lunar cycle. The tropical coenobitid hermit crab releases zoeae into the ocean within a few days of new moon (Amesbury 1980). Abundant fish larvae at night may also reflect spawning of reef fishes during moonless nights and high tides, which has been documented for many reef fishes (Johannes 1978). Although many siphonophores are motile (Barnes 1980), field observations of the small siphonophores (in the surface water and in buckets after collection) indicated that they are much less active than the other motile taxa examined.

For both pushnet and pullnet samples, there were few cases of interactions between methods and sites or dates, so either method appeared reasonably reliable.
Therefore, either method could be used to test hypotheses by comparing treatments with controls. In estimating parameters, however, in order to develop a model and make predictions, we would obtain different results from the 2 methods. The pushnet samples would have led us to estimate a greater survival of larvae from fewer eggs than we would have estimated from the pullnet samples.

The goals of scientific workshops and conferences are often to standardize sampling techniques. To monitor environmental quality for comparison to standards set by law, to do comparative regional surveys or studies of temporal variations of subjects such as larval fishes, or to test hypotheses concerning questions such as causes of environmental degradation, standardized sampling programs must be designed for consistency of data acquisition within the studies in order to permit statistical analysis. If there are no interactions of the sampling method with the parameters being estimated, then the bias in the method should be consistent across treatments and the resulting data should be valid for comparative studies or for testing hypotheses by comparing treatments with controls. However, in developing models of reality and estimating parameters, in exploratory surveys for assessment of latent resources, or in searching for unknown causes of sporadic phenomena, too much standardization can be detrimental. A variety of techniques should be used because all sampling techniques have their own limitations and biases. As Hamner \& Carleton (1979, p. 10) said 'The use of imprecise but distinctive sampling techniques provides greater credence in the final conclusion than would the use of a single technique, no matter how precise the replicates'.

Acknowledgements. Inspiration for this study came from a course on tropical blue-water zooplankton taught at the University of Guam Marine Laboratory by Bill Hamner. We are especially grateful to Frank Cushing, who designed and built the apparatus for operating the pushnet. We are also most grateful to Alicia W. Siegrist for helping us run multiway ANOVA on the UOG computer and to Chu-tak Tseng for programming the Box-Cox transformation determination on the computer. Vaughan Tyndzik was a great help with all the fieldwork. Thomas A. Clarke and Julie Bailey-Brock provided helpful suggestions on an earlier draft. Three anonymous reviewers also provided good suggestions. The study was supported by University of Hawaii-University of Guam Sea Grant Project UG/R-2.

\section{LITERATURE CITED}

Amesbury, S. S. (1980). Biological studies on the coconut crab (Birgus latro) in the Mariana Islands. Univ. Guam Mar. Lab. Tech. Rep. No 66

Barnes, R. D. (1980). Invertebrate zoology. Saunders, Philadelphia

Hamner, W M., Carleton, J. H. (1979). Copepod swarms: 
attributes and role in coral reef ecosystems. Limnol. Oceanogr 24 (1): 1-14

Hillmann-Kitalong, A. (1983). Two-year study of temporal variation in zooplankton communities in an inner region of Apra Harbor, Guam. M.S. thesis, Univ. of Guam

Johannes, R. E. (1978). Reproductive strategies of coastal marine fishes in the tropics. Environ. Biol. Fish. 3: 65-84

Kriete, W. H., Jr., Loesch, J. G. (1980). Design and relative efficiency of a bow-mounted pushnet for sampling juvenile pelagic fishes. Trans. Am. Fish. Soc. 109: 649-652
Miller, J. M. (1973). A quantitative push-net system for transect studies of larval fish and macrozooplankton. Limnol. Oceanogr. 18: 175-178

Randall, R. H., Eldredge, L. G. (ed.) (1982). Assessment of the shoalwater environments in the vicinity of the proposed OTEC development at Cabras Island, Guam. Univ. Guam Mar Lab. Tech. Rep. No 79

Sokal, R. R., Rohlf, F. J. (1981). Biometry, Freeman, San Francisco

This article was submitted to the editor; it was accepted for printing on March 6, 1987 